\title{
Bioactive Properties of Fruit Juice of Pomegranate (Punica granatum) Grown in Dry Regions of Sri Lanka
}

\author{
D.I.M. Amararatne, W.A.P. Weerakkody ${ }^{1 *}$ and J.A.L.P. Jayakody ${ }^{2}$ \\ Postgraduate Institute of Agriculture \\ University of Peradeniya \\ Sri Lanka
}

\begin{abstract}
Pomegranate (Punica granatum) is a popular fruit in Sri Lanka, rich with medicinal properties and extensively used in traditional Ayurvedic medicines. Total phenolic content, vitamin $C$ and antioxidant activity of the fruit (aril) juice were determined in fruits harvested from three locations in the southern dry zone (DL 1a). The total phenolic content and vitamin $C$, as determined by the Folin-Ciocalteau method, were $22.2 \pm 6.5$ and $8.7 \pm 2.3$ $\mathrm{g} / \mathrm{L}$, respectively, but significantly lower than that of pomegranate collected from Chilaw, $a$ popular pomegranate growing area in the north-west (DL 3). However, the antioxidant capacity of the fruit juice of pomegranate from $D L 1$ a was comparable with the same of DL 3. Antioxidant capacity of pomegranate fruit juice was positively correlated with total phenol content and vitamin $C$ content. The results revealed the bioactive properties of fruit juice extracted from local pomegranate trees grown in home gardens of the southern dry region of Sri Lanka, emphasizing potential exploitations of these properties of pomegranate in the fruit juice industry.
\end{abstract}

Keywords: Pomegranate, total phenolic count, antioxidant capacity, Vitamin C

\section{INTRODUCTION}

Epidemiological studies suggest that a high intake of food rich in natural antioxidants increases the antioxidant capacity of the plasma and reduces the risk of some, but not all, cancers, heart diseases, and stroke (Wang et al., 1996). According to The World Health Report 2002, low fruit and vegetable intake is estimated to cause about $31 \%$ of ischaemic heart disease and $11 \%$ of stroke worldwide. As a consequence, diet related chronic diseases caused $18.3 \%$ of all deaths in Sri Lanka in the mid-1990s. Since 1998 ischaemic heart disease has taken the first place for hospital deaths in Sri Lanka (Annual Health Statistics, 2007).

Pomegranate fruit (Punica granatum L.) is one of the most popular fruits in Sri Lankan home gardens; especially in dry and intermediate zones. The edible parts of pomegranate fruits can be consumed fresh or in processed form. It has valuable compounds in different parts of the fruit whose functional and medicinal effects such as antioxidant, anticancer and antiatherosclerotic effects have been confirmed (Mertens-Talcott et al., 2006; Perze-Vincent et al., 2002). Many scientists in the world have investigated the phenolic compounds and

\footnotetext{
Department of Crop Science, Faculty of Agriculture, University of Peradeniya, Peradeniya, Sri Lanka Department of Food Science and Technology, Faculty of Agriculture, University of Peradeniya, Peradeniya, Sri Lanka

* Author for correspondence: palithaw@pdn.ac.lk
} 
antioxidant activity in pomegranate juices of many varieties. The present studies was undertaken to investigate the bioactive properties of pomegranate juice extracted from the local varieties found in Sri Lankan home gardens.

\section{MATERIALS AND METHODS}

Pomegranate fruits at the edible stage were collected from dry zone home gardens in the Southern dry zone (Hambantota district) to determine their bioactive properties. Samples were collected from Angunukola palassa (A'palassa), Sooriyawewa and Weerawila (DL 1b) and compared with the same from a popular pomegranate growing area in the North-west in Arachchikattuwa (A'kattuwa) (DL 3) during the Yala season. Fruits were harvested from three to four plants from each location separately into perforated polyethylene bags. Fruits with defects (sun-burns, cracks, cuts, and bruises in husk) were discarded as practiced by Alighourchi et al. (2008). Properly cleaned fruits were peeled out and seeds and juicy rind of pomegranate were collected to a cotton cloth for extraction of juice by squeezing. Filtrates were stored in labeled plastic bottles under $-20^{\circ} \mathrm{C}$ after sealing with Parafilm. All measurements were conducted in triplicates as reported by Ahmed and Seerat (2009). Half of frozen samples were centrifuged for $20 \mathrm{~min}$ at $2500 \mathrm{rpm}$ and $2 \mathrm{ml}$ of the supernatant was filtered for 3 min through a $0.45 \mu \mathrm{m}$ syringe filter and collected into labeled eppendorf tubes. Then $20 \mu \mathrm{l}$ of filtrate was mixed with $980 \mathrm{ml}$ distilled water and vortexed for $5 \mathrm{sec}$ in high velocity (Vergara-Infante, 2008). Three dilutions were prepared for each sample.

Determination of total phenolic content (TPC): $100 \mu \mathrm{l}$ of diluted juice sample was measured in to an eppendorf tube and $500 \mu \mathrm{l}$ of $10 \%$ Folin-Ciocalteu reagent was mixed with it by shaking for $3 \mathrm{~min}$ at room temperature. Then $500 \mu \mathrm{l}$ of $6 \% \mathrm{Na} 2 \mathrm{CO} 3$ was added and shook for $15 \mathrm{~min}$ at room temperature. Spectrophotometer reading was taken at $600 \mathrm{~nm}$ promptly. A calibration curve was prepared with gallic acid and the results were expressed as mg of gallic acid equivalents (GAE) per liter of fresh juice (Velioglu et al., 1998).

Determination of Vitamin C: The sample extraction prepared for total phenolics analysis was used to measure the vitamin $\mathrm{C}$ content too. Differently, the spectrophotometer reading was taken at $600 \mathrm{~nm}$ promptly after adding Folin-Ciocalteu reagent and shaking for $3 \mathrm{~min}$. Gallic acid was used to prepare the standard curve (Velioglu et al., 1998).

Determination of antioxidant capacity (AOC): FRAP reagent was prepared by mixing 30 $\mathrm{ml}$ acetate buffer $(300 \mathrm{mmol} / \mathrm{L}$; $\mathrm{pH} 3.6)$, and ferric chloride $(20 \mathrm{mmol} / \mathrm{L})$ with $3 \mathrm{ml}$ of 2,4,6tripyridil-s-triazin $(10 \mathrm{mmol} / \mathrm{L})$ solution. $40 \mu \mathrm{l}$ of diluted samples were mixed with $120 \mu \mathrm{l}$ of distilled water and $800 \mu \mathrm{l}$ of FRAP reagent in labeled eppendorf tubes and shook for 10$15 \mathrm{sec}$ at room temperature. After $4 \mathrm{~min}$ of reaction period spectrophotometer reading was taken at $600 \mathrm{~nm}$ wave length. A range of iron sulfate concentrations from 500 to 2500 $\mu \mathrm{mol} / \mathrm{L}$ was used to prepare the calibration curve (Benzie \& Strain, 1996).

Simple Linear Regression procedure was followed for calibration of standard curves. Statistical analysis of data were done through one-way analysis of variance (ANOVA) and was followed by Duncan's Multiple Range Test, using statistical software, SAS. 


\section{RESULTS AND DISCUSSION}

\section{Total phenolic content and Vitamin C}

The TPC of pomegranate juice was significantly lower (at $\mathrm{p}=0.01$ ) in the locations in the Southern dry zone (7.7-13.7 mg/L), compared to Arachchikattuwa; DL $3(21.7 \mathrm{mg} / \mathrm{L})$. TPC of the fruit juices taken from fruits harvested from three sampling locations in the Southern dry zone (DL 1b) was not significantly different among each other (Fig. 1). The TPC found were towards the higher side of the ranges reported for exotic varieties (Weerakkody et al., 2009).

Vitamin $\mathrm{C}$ content of pomegranate juice was in the range of $6.3-8.4 \mathrm{mg} / \mathrm{L}$ among the sampling locations within the agro-ecological region (DL 1b). These were significantly lower than the vitamin C content found in the samples from Arachchikattuwa (11.02 mg/L of juice) (Fig. 1).

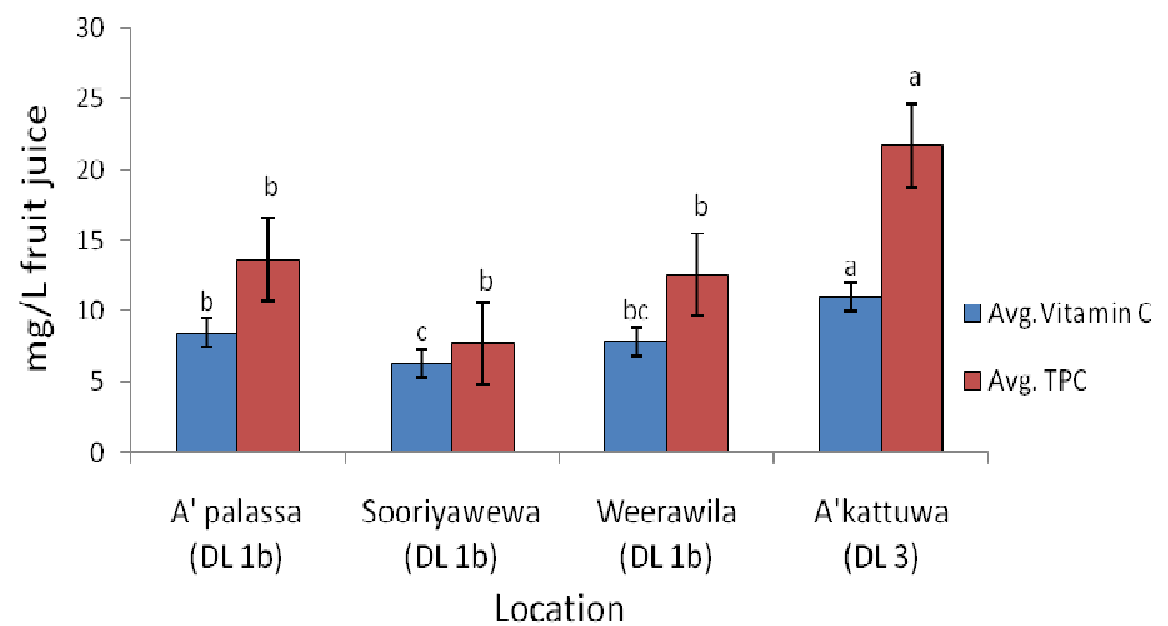

Fig. 1. Total phenolic content and Vitamin $\mathrm{C}$ of pomegranate juice

(Means followed by the same letter are not significantly different at $\mathrm{p}=0.05$ )

\section{Antioxidant capacity}

The AOC was not significantly different among the locations (17-33 mmol/L). Similar to the trend shown by the two juice parameters discussed above, the AOC of the fruit juice from DL 3 (87.6 mmol/L juice) was apparently higher than the same from DL 1b (Fig. 2). 


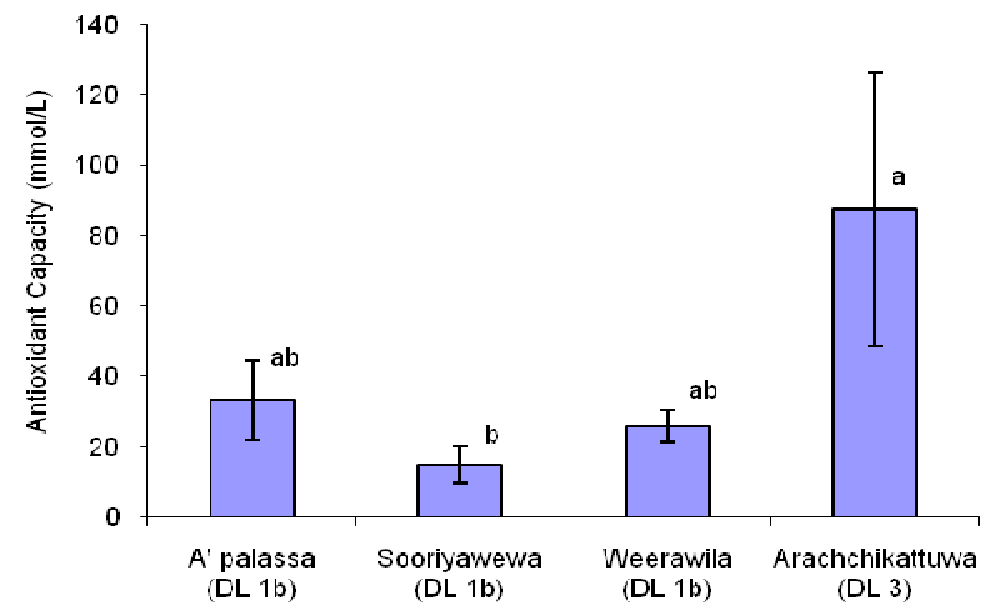

Fig. 2. Antioxidant capacity of pomegranate juice in four locations

Means followed by the same letter are not significantly different at $\mathrm{p}=0.05$ )

\section{Correlations between different bioactive measures of pomegranate juice}

It was evident that there is a significant correlation between vitamin $\mathrm{C}$ content and $\mathrm{AOC}$ $\left(\mathrm{R}^{2}=0.943\right)$. A positive relationship $\left(\mathrm{R}^{2}=0.944\right)$ was also observed between AOC and TPC of pomegranate fruit juice.

\section{CONCLUSIONS}

Preliminary tests for bioactive properties of pomegranate fruit (aril) juice revealed that total phenolics and vitamin $\mathrm{C}$ contents are found within $7.7-13.6 \mathrm{mg} / \mathrm{L}$ and $6.3-8.5 \mathrm{mg} / \mathrm{L}$, respectively in the Southern dry zone (DL 1b) and are significantly lower than the reference location, Arachchikattuwa (in agro-climatic region, DL 3). However, this difference was not revealed with respect to the AOC of pomegranate juice $(40.4 \pm 16.2 \mathrm{mmol} / \mathrm{L})$ despite the fact that $\mathrm{AOC}$ is positively correlated with the total phenolic and vitamin $\mathrm{C}$ contents. Further research can be suggested to examine the influence of region-based agro-climatic differences on the bioactive properties of pomegranate fruit juice.

\section{REFERENCES}

Benzie I. and Strain J.J. (1996). The ferric reducing ability of plasma (FRAP) as a Measure of "Antioxidant Power": The FRAP Assay. Analytical Biochem. 239, 70-76.

Annual health statistics (2007). Ministry of Health Services, Sri Lanka.

Alighourchi, H., Mohsen, B. and Soleiman, A. (2008). Anthocyanins characterization of 15 Iranian pomegranate (Punica granatum L.) varieties and their variation after cold storage and pasteurization, Eur. Food Res. Technol. 227, 881-887. 
Ahmed, S. and Seerat, H.B. (2009). Ascorbic acid, Carotenoids, Total phenolic content and antioxidant activity of various genotypes of Brassica Oleracea encephala. J. Med. and Biol. Sci. 3 (1), (Available

http://www.scientificjournals.org/journals2009/articles/1455.pdf)

Mertens-Talcott, S.U., Jilma-Stohlawetz, P., Rios, J., Hingorani, L. and Derendorf, H. (2006). Absorption, metabolism and antioxidant effects of pomegranate (Punica granatum L.) polyphenols after ingestion of a standardized extract in healthy human volunteers. J. Agric. Food Chem. 54, 8956-8961.

Perze-Vicente, A., Izquierdo, A. and Garcia-Viguera, C. (2002). In vitro gastrointestinal digestion study of pomegranate juice phenolic compounds, anthocyanins and vitamin C. J. Agric. Food Chem. 50, 2308-2312.

The World Health Report, Reducing risks, promoting health. (2002). World Health Organization, Geneva.

Velioglu Y.S., Mazza G., Gao L. and Oomah B.D. (1998) Antioxidant activity and total phenolics in selected fruits, vegetables and grain products. J. Agric. Food Chem. 46, 41134117.

Vergara-Infante, M.M. (2008). Stability of bioactive gompounds in aril Juice of Pomegranate under Cold Storage, M.Sc. Thesis, Faculty of Agri, Food and Environment, University of Sydney, Australia.

Wang, H., Cao, G. and Prior, R.L. (1996).Total antioxidant capacity of fruits. J. Agric. Food Chem. 44, 701-705.

Weerakkody, P. Jobling, J. Vergara Infante, M.M. and Rogers, G. (2009). The effect of maturity, sunburn and the application of sunscreens on the internal and external qualities of pomegranate fruits grown in Australia. Sci. Hort. 124(1), 57-61. 